\title{
Sistemas de Valores e Atitudes Democráticas de Estudantes Universitários
}

\author{
Cícero Pereira $^{1}$ \\ Ana Raquel Rosas Torres \\ Thaís S. Barros \\ Universidade Católica de Goiás
}

\begin{abstract}
RESUMO - Este artigo analisa os sistemas de valores de estudantes universitários e a relação desses sistemas com a atitude em relação à democracia. Para tanto, aplicou-se o Questionário de Valores Psicossociais e a Escala de Atitudes em Relação à Democracia a 284 estudantes de uma universidade da cidade de Goiânia (Brasil). Na análise das dimensões subjacentes à estrutura e ao conteúdo dos sistemas de valores, considera-se a teoria de Schwartz sobre os tipos motivacionais e a teoria de Inglehart sobre os valores materialistas e pós-materialistas. Os resultados mostram que os valores se organizam em função de quatro sistemas: o hedonista, o religioso, o materialista e o pós-materialista. Constata-se também que a adesão aos valores materialistas contribui para uma atitude negativa em relação à democracia, enquanto que a adesão aos valores pós-materialistas contribui para uma atitude positiva. A discussão girou em torno da similaridade entre estes resultados e os obtidos em estudos anteriores.
\end{abstract}

Palavras-chave: sistema de valores; atitude; democracia.

\section{Value Systems and Democratic Attitudes in University Students}

\begin{abstract}
This study analyses university students' value systems and the relationships among these systems and their attitudes towards democracy. Two hundred and eighty-four university students from Goiânia (Brazil) answered the Psychosocial Values Questionnaire and the Scale of Attitudes Towards Democracy. Schwartz's Theory about motivational types of values and Inglehart's Theory on materialist and pos-materialist values were used to analyse the underlying dimensions of structure and content of students' value systems. The results showed that the values were organized according to four systems: hedonist, religious, materialist and pos-materialist. Besides this, the results also indicated that adhesion to materialist values was negatively correlated to democracy while the adhesion to pos-materialist values contributes to a positive attitude towards democracy. The similarities among these results and previous studies are discussed.
\end{abstract}

Key words: value systems; attitudes; democracy.

Atualmente, a população dos países latino-americanos tem assistido com perplexidade às notícias sobre crises profundas na estrutura econômica e política desses países, o que pode comprometer a democracia no continente. Exemplos disso são: a ascensão de Eduardo Duhalde à presidência da Argentina através de mecanismos alheios ao voto direto do cidadão e, de forma mais grave, o golpe militar frustrado que tentou derrubar o presidente Hugo Chávez na Venezuela. Esses exemplos trazem à tona o debate sobre a fragilidade do processo democrático emergente nos países latino-americanos e coloca em evidência a necessidade de se compreender os fatores subjacentes à adesão dos grupos sociais aos princípios democráticos. Nesse sentido, os valores subjacentes aos princípios democráticos são apontados como requisitos para a estabilidade e efetividade de um sistema democrático (Finkel, Sigelman \& Humphries, 1999). Os valores, por serem centrais na organização das atitudes (Rokeach, 1968), são considerados a base da construção e manutenção dos sistemas políticos (Cochrane, Billig \& Hogg, 1979; Lipset, 1982; Rokeach, 1979a; Tetlock, 1986).

Nos estudos dos valores, são identificadas diferentes abordagens teórico-metodológicas sobre a sua natureza e sobre as dimensões que organizam os diversos valores vigentes em

1 Endereço: Grupo de Pesquisa em Processos Grupais Caixa Postal 12900, Goiânia, GO, Brasil 74643-970. E-mail:cicero.psi@ucg.br uma sociedade. As principais abordagens são as teorias de Rokeach (1973) sobre a hierarquia de valores individuais, de Schwartz (1992) sobre os tipos motivacionais e de Inglehart (1991) sobre valores materialistas e pós-materialistas. Temse desenvolvido no Brasil uma abordagem societal sobre os valores que faz a articulação entre uma perspectiva psicologizante dos valores e uma perspectiva sócio-política (Pereira \& cols., 2001; Pereira, Da Costa \& Camino, 2002; Pereira, Lima \& Camino, 2001; Torres \& cols., 2001). No presente artigo, procura-se validar esta abordagem através da analise dos sistemas de valores de universitários de Goiânia e da relação desses sistemas com a atitude dos estudantes em relação à democracia.

\section{Os valores psicossociais}

Com base na articulação psicossociológica proposta por Doise $(1976,1982)$ e explicitada por Camino (1996) como sendo o campo de estudo específico da psicologia social, tem-se desenvolvido no Brasil uma perspectiva teóricometodológica sobre os valores (Lima \& Camino, 1995; Pereira, 2000; Pereira \& cols., 2001; Torres, 1992) que, seguindo as idéias de Doise (1982), propõe estudar os sistemas de valores de diversos grupos sociais articulando explicações psicológicas para a organização dos valores, como a desenvolvida por Schwartz (1992), com explicações sociológicas, como 
a explicitada por Inglehart (1991). Schwartz (1992), pressupondo que o significado dos valores descreve um conjunto de necessidades individuais, identifica dez tipos motivacionais na forma como os indivíduos de diferentes culturas atribuem significados aos seus valores: poder, realização, hedonismo, estimulação, autodireção, universalismo, benevolência, tradição, conformidade e segurança. Além disso, Schwartz (1994) identifica duas dimensões bipolares que, ao expressar relações de compatibilidade ou conflito entre as motivações individuais, são responsáveis pela organização dos tipos motivacionais: abertura à mudança versus conservação; autotranscendência versus autopromoção. Inglehart (1991), considerando os valores como indicadores sociológicos das mudanças culturais, descreve como o desenvolvimento político e econômico em um conjunto de sociedades capitalistas favoreceram a emergência de valores materialistas e pós-materialistas. Igualmente, esse autor descreve como a emergência desses valores também contribuiu para o desenvolvimento do capitalismo.

Com a finalidade de integrar explicações psicológicas e sociológicas em uma abordagem psicossocial dos valores, Pereira e cols. (2002) definiram os valores como conhecimentos socialmente estruturados a partir dos diversos conteúdos ideológicos contidos no interior de uma sociedade. Essa abordagem não identifica necessidades individuais como fonte dos valores, mas aponta as identidades ideológicas, que orientam os interesses dos grupos sociais, como as repensáveis pela organização dos conteúdos dos valores (Da Costa, 2000). Com base nessa definição, tem-se realizado várias pesquisas no Brasil utilizando o Questionário de Valores Psicossociais (QVP), com o qual têm-se identificado as dimensões psicossociais que dão sentido aos sistemas que organizam os conteúdos dos valores. Inicialmente, Torres (1992) apresentou nove valores descritores de sistemas políticos (QVP-9) a estudantes universitários que atribuíram notas, variando entre um e dez, em função da importância de cada valor para a construção de uma sociedade ideal. Os resultados mostraram que os valores configuram-se em dois sistemas: democrático e autoritário. Em outro estudo, Lima e Camino (1995), pressupondo a relação dos valores com outras dimensões da vida cotidiana das pessoas, acrescentaram oito novos valores à versão anterior da escala, formando o QVP-17. Esses autores constataram a existência de cinco fatores subjacentes aos valores de universitários paraibanos: bem-estar individual, bem-estar econômico, religioso, igualitário e libertário. Em outros dois estudos, Pereira, Lima e Camino (1997) e Lima (1997) acrescentaram, com base numa pesquisa piloto, mais oito valores à escala, definindo o QVP-25, identificando cinco sistemas subjacentes aos valores da escala: bem-estar social; bem-estar individual; bem-estar profissional; religioso; bem-estar econômico.

Para identificar as dimensões sobre as quais esses sistemas estavam configurados, Pereira, Lima e Camino (2001) realizaram duas novas pesquisas aplicando o QVP-25 e combinaram os resultados de duas técnicas estatísticas - a Hierarchical Cluster Analysis (HCA) (Aldenderfer \& Blashfild, 1984) e a Multidimensional Scaling (MDS) (Kruskal \& Wish, 1978) - para identificar a estrutura e os conteúdos dos sistemas de valores de universitários da cidade de João Pessoa. Seus resultados mostram os valores organizados em três sistemas: o materialista, o religioso e o pós-materialista. Este último sistema foi formado por três subsistemas: bemestar social, bem-estar individual e bem-estar profissional. Os coeficientes de fidedignidade dos sistemas foram adequados em dois estudos (alfas variando de 0,74 a 0,92). Para comparar organização dos valores de estudantes universitários da Paraíba em relação a estudantes da Região Sul do Brasil, Pereira e cols. (2001) realizaram duas investigações aplicando o QVP-25 em amostras de universitários de Florianópolis e de Porto Alegre. Nas duas cidades, os sistemas foram iguais aos verificados nos estudantes de João Pessoa e os coeficientes de fidedignidade também foram elevados (alfas variando de 0,80 a 0,92, em Porto Alegre, e de 0,79 a 0,92, em Florianópolis).

Em duas novas investigações, Pereira e cols. (2002) analisam a convergência dos sistemas de valores com os tipos motivacionais (Schwartz, 1992) e apresentam a versão final do instrumento: o QVP-24. O primeiro passo foi a inclusão de três novos valores ao QVP (sensualidade, sexualidade e uma vida excitante) uma vez que esse instrumento até então não contemplava um conjunto de valores hedonistas, identificados em diferentes culturas (Schwartz \& Bardi, 2001), e a retirada de itens repetitivos. Em seguida, Pereira e cols. (2002) aplicaram o QVP-24 juntamente com o questionário de valores elaborado por Schwartz (1992), validado no Brasil por Tamayo e Schwartz (1993), a uma amostra de universitários paraibanos. Os resultados mostram valores organizados em quatro sistemas: hedonista, religioso, materialista e pós-materialista. As correlações desses sistemas com os tipos motivacionais (Schwartz, 1994, 1996) revelam semelhanças entre o conteúdo do sistema materialista e os valores de autopromoção (poder e realização), ao passo que, no conteúdo do sistema pós-materialista, estão contidos valores de autotranscendência (universalismo e benevolência) e de autodireção. O conteúdo do sistema religioso representa os valores de conservação (conformidade, tradição e segurança), enquanto o sistema hedonista representa os tipos motivacionais da estimulação e do hedonismo. No segundo estudo, Pereira e cols. (2002) aplicaram o QVP-24 a uma amostra de estudantes universitários e, com base em uma análise fatorial confirmatória, comprovaram a existência de quadro sistemas organizadores dos valores dos universitários: hedonista (prazer, uma vida excitante, sexualidade e sensualidade), religioso (obediência às leis de Deus, religiosidade, salvação da alma e temor a Deus), materialista (riqueza, autoridade, status e lucro) e pós-materialista, constituído pelos subsistemas do bem-estar social (justiça social, liberdade, igualdade e fraternidade), bem-estar individual (alegria, amor, conforto e auto-realização) e bem-estar profissional (realização profissional, dedicação ao trabalho, responsabilidade e competência). Os coeficientes de fidedignidade dos sistemas são adequados (alfas variando de 0,70 a 0,87 ). Esses mesmos quatro sistemas também foram confirmados através de uma análise fatorial confirmatória por Moraes (2002) em amostras de adolescentes paraibanos dos ensinos fundamental e médio.

Em resumo, os estudos utilizando o QVP-24 revelam que esse instrumento apresenta parâmetros de validade e de fidedignidade adequados para a análise dos sistemas de valores de estudantes universitários, sobretudo de universitários 
paraibanos. A questão que se coloca é a de saber se esse instrumento também é adequado para avaliar os valores de universitários de Goiânia e como esses valores influenciam as atitudes dos estudantes em relação à democracia.

\section{Influência dos sistemas de valores nas atitudes políticas: estudos empíricos}

A influência dos valores na política tem sido freqüentemente analisada (Lipset, 1982; Schwartz \& Bardi, 1997). Nesse sentido, Rokeach $(1968,1979 b)$ propôs o "Modelo dos Dois Valores Políticos" que descreve o conflito entre liberdade e igualdade como sendo a dimensão organizadora das diferenças entre ideologias políticas individualistas e coletivistas (Kinder \& Sears, 1985). Analisando textos das principiais ideologias políticas, Rokeach (1973) verifica, nos escritos comunistas, a prioridade da igualdade sobre a liberdade e, no texto capitalista, a prioridade da liberdade sobre a igualdade. No texto socialista, ambos são altamente ressaltados, ao passo que no texto nazista são pouco enfatizados. Com base nesse resultado, Rokeach (1973) defende que as atitudes políticas poderiam estar determinadas pela adesão aos valores liberdade e igualdade. Para submeter à prova essa hipótese, Cochrane e cols. (1979) realizaram uma investigação na cultura britânica constatando que apenas a igualdade diferencia a adesão dos britânicos às doutrinas políticas, de modo que os comunistas e os socialistas dão maior importância a esse valor que os fascistas e os conservadores. Essa mesma tendência foi constatada na Austrália numa série de pesquisas mostrando que quanto maior a adesão à igualdade, menor é a probabilidade dos australianos votarem em candidatos conservadores (Feather, 1979, 1984, 1989). Embora essas pesquisas revelem a liberdade e a igualdade relacionadas com as orientações políticas, as pesquisas mais recentes indicam que os posicionamentos políticos não são mais guiados por dois valores isoladamente, mas por muitos valores agindo em conjunto (Braithwaite, 1994; Tamayo, Pimenta, Rolim, Rodovalho \& Castro, 1996).

Nesse sentido, Barnea e Schwartz (1998) empregaram a teoria dos tipos motivacionais de valores para explicar as dimensões responsáveis pelo voto de cidadãos israelenses. Esses autores constataram que os israelenses organizam as suas escolhas políticas a partir de uma ideologia mais democrática, característica do liberalismo clássico, e de uma ideologia mais autoritária, fundamentada na manutenção da ordem social através da organização religiosa. Constataram também que a adesão aos valores de autotranscendência influencia positivamente a preferência por partidos com ideológica democrática e negativamente a opção por partidos de ideologia religiosa; ao passo que a adesão aos valores de conservação influencia negativamente a preferência por partidos democráticos e positivamente a escolha por partidos religiosos. Também aplicando o modelo de Schwartz (1992), Tamayo e cols. (1996) verificaram que a adesão de estudantes universitários brasileiros aos valores de autotranscendência e de abertura a mudança influencia de forma positiva a sua preferência pela esquerda política e de centro e negativamente a opção pela direita.

Numa perspectiva psicossociológica, Torres (1992) mostra que a adesão de estudantes universitários paraibanos aos valores autoritários diminui a aceitação do socialismo e a identificação com a esquerda. Utilizando o QVP-17, Lima e Camino (1995) observam que a adesão aos valores igualitários, libertários e do bem-estar individual influencia a participação política e a atitude favorável à esquerda, enquanto a preferência por valores religiosos e econômicos reduz a simpatia por partidos de esquerda. Posteriormente, Pereira e cols. (1997), aplicando o QVP-25, constam que os valores econômicos e religiosos reduzem os indicadores do exercício da democracia, como a participação política, a identificação partidária e a disposição a votar.

Mesmo apontando alguns indicadores da influência dos valores na democracia, o conjunto de investigações descrito anteriormente não tem avaliado a relação dos sistemas de valores com uma medida de atitude frente à democracia. Um dos fatores, que pode ter contribuído para isso, talvez seja a escassez de instrumentos com parâmetros psicométricos adequados para avaliar a atitude em relação à democracia. De fato, embora exista na literatura internacional um número razoável de escalas construídas para avaliar o posicionamento dos indivíduos em relação à democracia (Finkel \& cols., 1999), os parâmetros psicométricos desses instrumentos são questionáveis. Nesse sentido, a maioria dos instrumentos sobre atitudes democráticas não apresenta indicadores de validade e fidedignidade, tais como a Escala de Princípios Fundamentais da Democracia (Prothro \& Grigg, 1960), a Escala de Aplicação dos Princípios Democráticos (McClosky, 1964) e o Î́ndice de Orientação Pró-Democracia (Miller, Hesli \& Reisinger, 1995; Reisinger, Miller, Hesli \& Maher, 1994). Mesmo quando os instrumentos mostram algum grau de validade, não apresentam indicadores confiáveis de fidedignidade, como a Escala de Adesão à Democracia (Weil, 1989, 1993), a escala de Atitudes em Frente à Democracia (Whitefield \& Evans, 1996) e a escala de Adesão aos Princípios Democráticos (Kaase, 1971). Do mesmo modo, quando apresentam algum grau de fidedignidade, não mostram coeficientes de validade confiáveis, tais como a Escala de Valores Democráticos (McClosky \& Zaller, 1984) e a Escala Multidimensional de Valores Democráticos (Gibson, Duch \& Tedin, 1992). Além disso, esses instrumentos avaliam as atitudes dos indivíduos em relação à democracia em culturas diferentes da latino-americana em geral e da brasileira em particular, o que mostra a necessidade de contextualizar as dimensões sobre as quais são desenvolvidas as atitudes democráticas na América Latina e no Brasil.

$\mathrm{Na}$ ausência de consenso sobre o significado da democracia (Bobbio, 1986, 1991; Schmitter, 1997; Touraine, 1996), Da Costa (2000) analisa o significado de um país plenamente democrático em estudantes universitários brasileiros. Esse autor constata que os estudantes têm uma visão hegemônica da democracia, identificando quatro categorias responsáveis pelas diversas conotações que a democracia pode assumir: visão de valor, que descreve a democracia com base nos princípios de liberdade e igualdade; visão de cidadania, que descreve a democracia com base na participação política do cidadão nas decisões governamentais; visão formal, que descreve a democracia a partir de aspectos jurídicos e governamentais envolvidos na garantia das eleições e no cumprimento da Constituição; visão de resultados, que organiza os significados da democracia como um sistema 
político que garante o atendimento das necessidades básicas da sociedade e o desenvolvimento das potencialidades dos indivíduos. Com base nessas visões, Da Costa (2000) conclui que os universitários concebem a democracia como um ideal de organização da sociedade pautada sobre os valores do bem-estar social, sobre a participação dos cidadãos nas instituições políticas do Estado de Direito, sobre a realização pessoal e sobre o bem-estar individual.

Para compreender as dimensões sobre as quais se desenvolvem as atitudes democráticas no Brasil, Pereira, Lima e Camino (2001) estudaram como essas atitudes foram se desenvolvendo na história recente dos processos de democratização ocorridos no interior dos países latino-americanos. Para esses autores, a abertura política iniciada nos anos oitenta, aliada às sucessivas crises político-econômicas vividas por esses países, tem permitido que se desenvolva uma dimensão psicossociológica responsável pela organização das atitudes das pessoas em relação ao processo de democratização. Essa dimensão é formada por dois discursos opostos. Por um lado, cada vez mais os grupos e instituições da sociedade civil têm defendido os ideais democráticos como sendo essenciais para o respeito aos direitos individuais e para o desenvolvimento da sociedade (Giner, 1986; Lechner, 1994). Por outro lado, devido ao fato da abertura política não ter mostrado de forma objetiva melhorias econômicas e políticas, tem-se construído um discurso que questiona a utilidade do voto, as instituições democráticas (D'Adamo \& Beaudoux, 1995; Gouveia, França, Da Costa \& Camino, 1997) e os princípios subjacentes às democracias modernas (Baquero, 1994; De Riz, 1994; Offe, 1985), apontando a época das ditaduras militares como um período em que eram apresentadas soluções mais eficazes para os problemas sociais básicos (Camino, Torres \& Da Costa, 1995).

Com base na definição de democracia como um sistema político oposto aos sistemas de governos autoritários (Bobbio, 1993; Macpherson, 1978), Pereira \& cols. (2001) apresentam a dimensão democracia-ditadura como a responsável pela organização das atitudes das pessoas em relação à democracia. Para avaliar as atitudes de estudantes universitários de João Pessoa nesta dimensão, esses autores construíram a Escala de Atitudes em Relação à Democracia (EARD-4) que avalia o posicionamento de diversos grupos sociais em quatro itens, sendo que dois descrevem a adesão aos princípios democráticos e os outros dois descrevem a crença na eficácia da ditadura. Os resultados de uma análise fatorial mostraram que a atitude dos estudantes organiza-se em torno de um único fator bipolar, que opõe a democracia à ditadura. Além disso, Pereira e cols. (2001) constatam que a adesão aos valores pós-materialistas influencia a atitude favorável à democracia, enquanto a adesão aos valores religiosos influencia negativamente essa atitude.

Esse mesmo tipo de influência foi constatado por Pereira e cols. (2001) em uma amostra de universitários da cidade de Porto Alegre. Com base em um modelo de equações estruturais, esses autores mostram que realmente os valores pós-materialistas de estudantes de Florianópolis influenciam positivamente a atitude democrática, mas são os valores materialistas que reduzem a adesão à democracia. Embora a EARD-4 se apresente como um instrumento conceitualmente válido para avaliar a atitude de estudantes universitários frente à democracia, essa escala também tem a mesma deficiência da maioria dos instrumentos que medem as atitudes democráticas: baixa fidedignidade. De fato, nos estudos realizados com a EARD-4, os coeficientes alfa variam de 0,60 a 0,68, indicando, assim, a necessidade desenvolver esse instrumento com a finalidade de minimizar seus problemas psicométricos. Nesse sentido, este artigo, para avaliar de forma mais precisa a influência dos valores de estudantes universitários em suas atitudes em relação à democracia, tenta melhorar os indicadores psicométricos dessa escala.

\section{Sistemas de valores e democracia em universitários de Goiânia}

Neste estudo, avalia-se a adequação da abordagem desenvolvida por Pereira e cols. $(2001,2002)$ para analisar a estrutura e os conteúdos dos sistemas de valores de universitários da cidade de Goiânia e a relação dos sistemas de valores com a atitude desses universitários frente à democracia. Com relação aos valores, esperam-se constatar os quatro sistemas identificados anteriormente: materialista, religioso, hedonista e pós-materialista. Com relação à democracia, a dimensão democracia-ditadura organizará o posicionamento dos estudantes em relação à democracia. Espera-se também encontrar uma relação positiva entre os valores pós-materialistas e a atitude frente à democracia, uma vez que no discurso democrático atual, eles são subjacentes à defesa dos valores que constituem esse sistema, tais como o bem-estar social e individual (Iñíquez \& Vázquez, 1995). Finalmente, os valores materialistas contribuirão com a atitude negativa frente à democracia (Inglehart, 1991), corroborando os resultados de pesquisas em que a adesão a esses valores contribui para o afastamento de universitários das instituições políticodemocráticas (Pereira \& cols., 2001).

\section{Método}

\section{Amostra}

Uma amostra composta por 284 estudantes, de ambos os sexos (sendo $78 \%$ do sexo feminino) de uma universidade localizada em Goiânia participou desta pesquisa, os quais apresentaram idade média de 24 anos $(D P=6,24)$. A definição da amostra levou em conta as proporções de alunos de Ciências Humanas, Biológicas e Exatas, assim como as proporções de alunos matriculados em disciplinas de início, meio e final de curso.

\section{Instrumento}

Os valores foram avaliados através do QVP-24, que foi desenvolvido nos estudos realizados por Pereira e cols. (2002). Este instrumento contém uma lista com vinte e quatro valores avaliados pelos estudantes, com notas variando entre um e dez, em função da importância de cada um dos valores para a construção de uma sociedade ideal para se viver. A lista de valores é a seguinte: alegria, amor, auto-realização, autoridade, competência, conforto, dedicação ao trabalho, fraternidade, igualdade, justiça social, liberdade, lucro, obediência às leis de Deus, prazer, realização profissional, 
religiosidade, responsabilidade, riqueza, salvação da alma, sensualidade, sexualidade, status, temor a Deus e uma vida excitante.

Avaliou-se a atitude em relação à democrática através da Escala de Atitudes em Relação à Democracia desenvolvida inicialmente por Pereira e cols. (2001). Considerando a fragilidade dessa escala em relação aos parâmetros psicométricos de fidedignidade (Pereira \& cols., 2001), resolveu-se acrescentar à escala um conjunto de vinte e seis itens, construídos a partir das categorias identificadas no estudo de Da Costa (2000) como sendo as responsáveis pela organização dos diversos significados da democracia. Para a construção dos itens foram seguidos os critérios estabelecidos na tecnologia da construção de instrumentos para a avaliação de construtos psicológicos (Pasquali, 1999). Assim, a escala avalia a atitude em relação à democracia através do posicionamento dos estudantes em trinta itens (Tabela 1), sendo portando chamada de EARD-30. Os estudantes indicaram o seu grau de concordância com cada um dos itens numa escala do tipo Likert (1970), que varia de 1 (discordo totalmente) a 7 (concordo totalmente). Os parâmetros psicométricos dessa escala são apresentados na seção dos resultados.

\section{Procedimentos}

Todos os questionários foram respondidos individualmente pelos estudantes, mas em situação coletiva em salas de aula definidas através de sorteio. Para a definição das salas, foi solicitada à direção da universidade a lista completa contendo a quantidade de alunos por curso, o nome dos cursos, a designação das disciplinas em cada curso, a localização e o horário de cada disciplina. Após a definição das salas, foram solicitadas aos professores responsáveis pelas disciplinas as autorizações para aplicação dos questionários. Não foram observadas recusas por parte dos professores nem por parte dos alunos para a realização da pesquisa.

\section{Resultados}

A configuração dos sistemas de valores foi obtida através dos mesmos procedimentos utilizados por Lima (1997), Pereira e cols. (2001) e Pereira e cols. (2002). Esses procedimentos combinam a aplicação de duas técnicas estatísticas: $H C A$ e $M D S$. A $H C A$ utiliza medidas de distâncias euclidianas entre as variáveis para identificar agrupamentos ou clusters de variáveis (Aldenderfer \& Blashfild, 1984). Na definição dos agrupamentos, foi utilizado o método desenvolvido por Ward (1963). Na MDS, as distâncias euclidianas permitem analisar os valores pressupondo a existência de dimensões psicossociais (os sistemas de valores) subjacentes à adesão dos estudantes a cada um dos valores da escala. O grau de ajustamento das variáveis às dimensões obtidas é medido pelo stress (Abelson, 1967), o qual deve apresentar coeficiente inferior a 0,15 para que as dimensões sejam adequadas para a interpretação dos resultados (Kruskal \& Wish, 1978). Os resultados da $H C A$ indicam a organização dos valores em quatro agrupamentos (sistemas). Os valores temor a Deus, religiosidade, salvação da alma e obediência às leis de Deus formam o sistema de valores religiosos. Os valores status, riqueza, lucro e autoridade constituem o sistema de valores materialistas. Os valores prazer, sexualidade, sensualidade e uma vida excitante descrevem o sistema hedonista. O quarto agrupamento reúne os valores do sistema pós-materialista, que é constituído por valores do bem-estar social (igualdade, liberdade, fraternidade e justiça social), do bem-estar individual (conforto, auto-realização, alegria e amor) e do bem-estar profissional (realização profissional, dedicação ao trabalho, competência e responsabilidade). Esses resultados encontram-se nos quadros pontilhados que envolvem os valores na Figura 1.

Os resultados da $M D S$ mostram (Figura 1) que apenas duas dimensões são utilizadas pelos estudantes para organizar seus valores (Stress $=0,09$ e $R^{2}=0,97$ ). A primeira dimensão contrapõe os valores materialistas aos valores pós-materialistas. A segunda dimensão foi constituída pela contraposição entre os valores religiosos e os hedonistas, o que permite considerar nas análises subseqüentes os quatro sistemas de valores. A fidedignidade desses sistemas foi analisada através do Alfa de Cronbach (1951), que indica coeficientes adequados para todos os sistemas: materialista ( $\alpha=0,84)$; pós-materialista $(\alpha=0,90)$; hedonista $(\alpha=0,82)$, religioso $(\alpha=0,84)$.

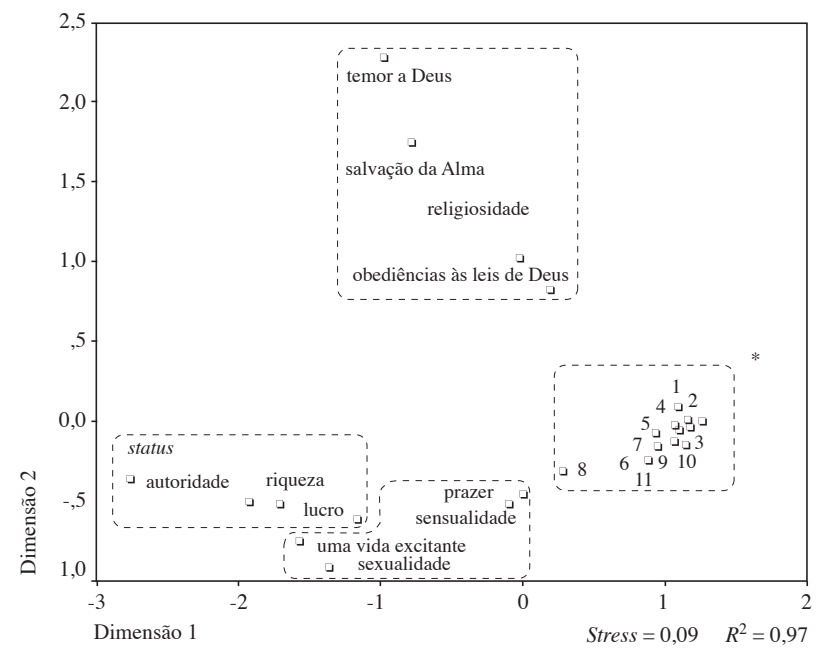

* Os valores contidos neste quadro são os seguintes: 1 = igualdade; 2 = liberdade; 3 = fraternidade; 4 = justiça social; 5 = alegria; $6=$ auto-realização $; 7=$ amor $; 8=$ conforto $; 9=$ realização profissional; $10=$ competência; $11=$ responsabilidade; $12=$ dedicação ao trabalho.

Figura 1. Representação gráfica dos resultados da Hierarchical Cluster Analysis e da Multidimensional Scaling aplicada aos escores de adesão dos estudantes aos valores do QVP-24

A análise da adequação teórica (validade de construto) da EARD-30 foi realizada através de uma análise fatorial, pelo método dos eixos principais, aplicada aos escores do posicionamento dos estudantes nos trinta itens da escala. Os resultados indicaram a existência de um único fator bipolar com eigenvalue igual a 6,8 que explica $23 \%$ da variabilidade dos posicionamentos. Contudo, dois itens da escala não apresentaram cargas fatoriais satisfatórias, o que mostra a necessidade de eliminá-los da escala. Após a eliminação desses itens, realizou-se outra análise fatorial sobre os vinte e oito itens restantes, cujos resultados (ver Tabela 1) indicam a existência de um único fator bipolar com eigenvalue igual a 6,7 que explica $24 \%$ da variabilidade da atitude em relação à 
Tabela 1. Cargas fatoriais, eigenvalue, variância explicada e fidedignidade da escala de atitudes em relação à democracia

\begin{tabular}{|c|c|}
\hline Itens da Escala & Cargas Fatoriais* \\
\hline A democracia é essencial para o bom funcionamento do nosso país & $-0,53$ \\
\hline Eu prefiro os ideais democráticos & $-0,53$ \\
\hline Acredito que a democracia tem que ser realmente estabelecida em nosso país & $-0,53$ \\
\hline A democracia é o melhor regime político para o nosso país & $-0,51$ \\
\hline Apenas a democracia garante a liberdade de escolha do indivíduo & $-0,50$ \\
\hline Acredito que na democracia as pessoas poderão se desenvolver plenamente & $-0,48$ \\
\hline A democracia é a esperança para o nosso país & $-0,46$ \\
\hline Quando o Brasil for democrático as pessoas poderão viver tranqüilamente & $-0,45$ \\
\hline A democracia no Brasil favorecerá ao nosso desenvolvimento cultural & $-0,41$ \\
\hline Na democracia as condições de realização pessoal são garantidas & $-0,40$ \\
\hline A democracia é um regime político competente & $-0,38$ \\
\hline O regime democrático é eficaz & $-0,38$ \\
\hline A participação de todos nas decisões políticas resolveria os problemas sociais & $-0,36$ \\
\hline As eleições são necessárias para se ter um bom governo & $-0,31$ \\
\hline Com a democracia teremos a garantia da igualdade de condições para todos & $-0,31$ \\
\hline O que falam sobre a ditadura militar é falso & 0,32 \\
\hline É melhor uma ditadura competente do que uma democracia incompetente & 0,32 \\
\hline Na ditadura as necessidades básicas da sociedade são realmente satisfeitas & 0,39 \\
\hline A defesa dos ideais democráticos leva a desordem social & 0,45 \\
\hline Eu prefiro a ditadura & 0,46 \\
\hline Uma ditadura forte acabaria com os problemas de nosso país & 0,53 \\
\hline Na época da ditadura militar o Brasil era um país socialmente justo & 0,57 \\
\hline A ditadura militar deveria voltar & 0,58 \\
\hline A ditadura é eficaz para resolver os problemas do Brasil & 0,59 \\
\hline Se estivéssemos numa ditadura não haveria tanta pobreza em nosso país & 0,59 \\
\hline Apenas uma ditadura organizaria o nosso país & 0,61 \\
\hline Na ditadura os direitos dos cidadãos são realmente satisfeitos & 0,64 \\
\hline A ditadura é necessária para o crescimento do Brasil & 0,70 \\
\hline Se uma única pessoa mandasse na política, haveria ordem social no Brasil & $* *$ \\
\hline O nosso país crescerá quando o poder ficar nas mãos de uma autoridade forte & $* *$ \\
\hline Eigenvalue & 6,7 \\
\hline Variância Explicada & $24 \%$ \\
\hline Fidedignidade da Escala (Coeficiente Alfa) & 0,90 \\
\hline
\end{tabular}

* Os itens com cargas fatoriais positivas foram invertidos no cálculo da fidedignidade da escala.

** Itens com cargas fatoriais inferiores a 0,30 .

democracia. Este fator organiza, no pólo negativo, a avaliação dos itens que descrevem as preferências pela democracia enquanto sistema político apropriado para o Brasil e, no pólo positivo, organiza as preferências pela ditadura como sistema de governo viável para o Brasil. A escala também apresenta uma fidedignidade muito boa com $\alpha=0,90$, permitindo a construção de um indicador do posicionamento dos estudantes em relação à democracia.

Com base na adesão dos estudantes a essa escala de atitudes frente à democracia, analisou-se a relação entre os sistemas de valores e a dimensão democracia-ditadura. Essa análise foi realizada através de um modelo de regressão linear múltipla. Foi necessária a utilização do método stepwise porque, embora as análises estejam baseadas em hipóteses sobre a relação entre os valores e a atitude em relação à democracia, as hipóteses não predizem a ordem de importância das variáveis antecedentes. De fato, esse método é o mais apropriado quando se procura explorar a influência de um conjunto de preditores (os sistemas de valores) sobre uma variável-critério (a atitude) na ausência de uma hierarquia teórica entre as variáveis preditoras (Tabchinick \& Fidell, 1996). Os resultados dessa análise (ver Tabela 2) permitem constatar que a adesão ao sistema de valores pós-materialista se relaciona positivamente com a atitude frente à democracia $(\beta=0,24 ; p<0,001)$, enquanto o sistema materialista apresenta uma relação negativa com essa atitude $(\beta=-0,15$; $p<0,05)$. Não foram observadas relações significativas entre os sistemas religioso e hedonista e a atitude dos estudantes em relação à democracia.

\section{Discussão}

Neste artigo, analisam-se a estrutura e os conteúdos dos sistemas de valores de estudantes universitários e a relação desses sistemas com a atitude desses estudantes em relação à democracia. A abordagem empregada na análise dos valores foi à desenvolvida por Pereira e cols. $(2001,2002)$ que articula a perspectiva psicológica de Schwartz (1992) sobre os tipos motivacionais e a abordagem sociológica de Inglehart (1991) sobre os valores materialistas e pós-materialistas. 
Tabela 2. Resultados da regressão múltipla usada para analisar a influência dos sistemas de valores na atitude dos estudantes em relação à democracia

\begin{tabular}{lrcc}
\hline \multirow{2}{*}{\multicolumn{1}{c}{ Sistemas de Valores }} & \multicolumn{3}{c}{$\begin{array}{c}\text { Atitude em Relação à } \\
\text { Democracia }\end{array}$} \\
\cline { 2 - 4 } & Beta & t & $p<$ \\
\hline Sistema de Valores Materialistas & $-0,15$ & $-2,14$ & 0,05 \\
Sistema de Valores Hedonistas & 0,09 & 1,11 & $\mathrm{n} . \mathrm{s}$ \\
Sistema de Valores Religiosos & $-0,08$ & $-1,20$ & $\mathrm{n} . \mathrm{s}$ \\
Sistema de Valores Pós-Materialistas & 0,24 & 3,50 & 0,001 \\
Coeficiente de Regressão Múltipla & \multicolumn{3}{c}{$R=0,25$} \\
Explicação da Variabilidade & \multicolumn{3}{c}{$R^{2}=0,06$} \\
Teste Estatístico & \multicolumn{3}{c}{$F(2,281)=6,987 ; p<0,001$}
\end{tabular}

Nota. A adesão aos sistemas de valores variam de 0 (menor adesão) a 10 (maior adesão). A atitude em relação à democracia varia de 1 (atitude desfavorável) a 7 (atitude favorável).

Os resultados da $H C A$ e da $M D S$ permitem constatar que os universitários de Goiânia organizam os valores que são importantes para uma sociedade ideal com base nos mesmos sistemas apontados por universitários de João Pessoa: o materialista, o religioso, o hedonista e o pós-materialista. Todos os valores que compõem o QVP-24 foram organizados de acordo com o esperado. Assim, o sistema materialista organiza os valores que propõem a realização econômica (riqueza e lucro) e a estratificação social (status e autoridade). O sistema religioso organiza os típicos do cristianismo (temor a Deus, a religiosidade, a obediência às leis de Deus e a salvação da alma). O sistema hedonista organiza os valores ligados ao prazer e a satisfação sexual. O sistema pós-materialista reúne, como proposto por Inglehart (1991) e por Pereira e cols. (2002), valores do bem-estar social, do bem-estar individual e do bem-estar profissional.

Embora o conteúdo dos sistemas de valores obtidos assemelhe-se aos motivacionais da teoria de Schwartz (1994, 1996), tal como explicitada por Pereira e cols. (2002), a perspectiva aqui adotada se diferencia da proposta por Schwartz (1992), uma vez que este autor prioriza nos valores a sua natureza individual conceituando-os como concepções individuais ancoradas nas necessidades humanas. Nesse sentido, Schwartz (1992), em sua abordagem, apresenta a organização dos valores pautada sobre possíveis relações de compatibilidade e conflito entre eles. De fato, por conterem um forte componente de desejabilidade social (Rokeach, 1973), era de se esperar que os valores apresentassem relações de compatibilidade em sua organização interna. Contudo, o segundo aspecto da organização dos tipos motivacionais - a relação de conflito - tem sido questionado (Gouveia, Martinez, Meira \& Milfont, 2001; Lima, 1997; Pereira \& cols., 2001). Esses questionamentos se referem ao fato de que os valores, por serem amplamente compartilhados, não poderiam apresentar relações de conflito entre si. Por sua vez, Schwartz (1994), ao considerar que os valores são individuais, baseia seu modelo num provável conflito de interesses entre as metas que os indivíduos adquirem ao longo da vida, interesses esses que por representarem necessidades individuais opostas, seriam conflitantes.

Em contrapartida, a perspectiva psicossocial adotada neste artigo não nega que os valores possam se relacionar às necessidades, mas considera que tanto os valores quanto às prioridades, ou necessidades, dos indivíduos são produções sociais (Deschamps \& Devos, 1993). Sendo assim, a fonte dos valores não seriam as necessidades, mas sim as diversas ideologias existentes sobre a natureza do indivíduo e da sociedade (Pereira \& cols., 2001). É nesse sentido que os valores são concebidos como produções sociais amplamente valorizadas pelos grupos sociais e seus sistemas, e que por serem valorizados, não poderiam apresentar relações de conflito em sua estrutura interna. De fato, análises complementares sobre as relações entre os sistemas de valores estudados neste artigo revelam que todas as correlações entre esses sistemas são positivas: materialista versus pós-materialista $(r=0,25$; $p<0,001)$; materialista versus religioso $(r=0,26 ; p<0,001)$; materialista versus hedonista $(r=0,58 ; p<0,001)$; pós-materialista versus religioso $(r=0,18 ; p<0,01)$; pós-materialista versus hedonista $(r=0,30 ; p<0,001)$; religioso versus hedonista $(r=0,20 ; p<0,01)$. Correlações positivas entre todos os sistemas de valores, assim como entre os tipos motivacionais, já haviam sido constatadas em outras investigações (Pereira \& cols., 2002), as quais sugerem uma revisão no postulado de Schwartz (1992) no que se refere às possíveis relações de conflito entre valores (Gouveia \& cols., 2001).

Essas correlações positivas também apontam a necessidade de uma re-interpretação da teoria de Inglehart (1977) sobre os valores materialistas e pós-materialistas. Inglehart (1991) considera que as sociedades que não solucionaram problemas sociais básicos dão mais importância às metas materialistas, ao passo que sociedades que atingiram um certo grau de solução desses problemas priorizam metas pós-materialistas. De fato, Inglehart (1991) tem constatado, em várias sociedades, que as metas a serem atingidas por um país são organizadas em torno de um fator bipolar que situa o materialismo de um lado e o pós-materialismo do outro (Inglehart, 1994). Contudo, em países em via de desenvolvimento os problemas sociais básicos, além da falta de solução, estão aumentando. Segundo Pereira e cols. (2001), nesses países é provável que os diversos grupos sociais considerem o sistema materialista importante para a organização da sociedade. Para esses autores, essa hipótese explica as correlações positivas constatadas entre os sistemas de valores e indicam que a ampla adesão aos valores pós-materialistas não implica redução na importância dos valores materialistas, uma vez que quanto mais centrais são os valores do bem-estar social, individual e profissional para a sociedade, mais os estudantes concordam que nessa sociedade devam prevalecer a autoridade, a riqueza, o lucro e o status.

Mas como explicar o fato dos sistemas aparecerem em lados opostos nos resultados da $M D S$ ( ver Figura 1)? De acordo com Lima (1997) e com Pereira, Lima e Camino (2001), a análise dos valores como estruturas de conhecimentos sociais, e não como indicadores de necessidades individuais, enfoca nos sistemas de valores, o fato deles descreverem a dimensão de desejabilidade social amplamente destacada nos sistemas sociais (Maio \& Olson, 1998). Em decorrência disso, a oposição dos valores projetados na figura geométrica produzida pela $M D S$ pode ser interpretada como um artefato metodológico também presente nos diversos estudos sobre valores que empregam esse tipo de análise de dados (Schwartz, 1992, 1994, 1996). Como mostram as correlações positivas constatadas entre os sistemas de valores, oposições entre eles 
não representam relações de conflitos axiológicos, uma vez que a técnica estatística utilizada força uma oposição entre variáveis que pode não descrever uma dimensão psicossocial capaz de organizar os posicionamentos dos grupos sociais (Lima, 1997). Essas explicações não excluem, necessariamente, a possibilidade desses sistemas influenciarem de forma oposta outras variáveis, como a atitude dos estudantes em relação à democracia. Assim, a oposição entre os sistemas pode representar conflitos ideológicos em uma determinada arena política e não disparidades entre interesses ou metas individuais (Pereira \& cols., 2001).

Na ausência de um instrumento válido e preciso para avaliar as atitudes em relação à democracia, tem-se constatado a necessidade de desenvolver uma escala de atitudes frente à democracia na América Latina e particularmente no Brasil (Lima, 1997; Pereira, Lima \& Camino, 2001). A escassez de escalas de democracia confiáveis tem levantado a hipótese de que a avaliação dos posicionamentos dos indivíduos em relação à democracia não poderia ser fidedigna, dado que não há um consenso sobre o que significa a democracia (Da Costa, 2000). Contudo, os resultados da análise fatorial e do coeficiente alfa aplicados a EARD-30 permitem refutar essa possibilidade e considerar esse instrumento conceitualmente válido e fidedigno para descrever a dimensão democraciaditadura. Como mencionado anteriormente, essa dimensão, também constatada em outras investigações (Lhullier, 1996), organiza as atitudes dos grupos sociais com base na oposição entre a defesa dos ideais democráticos e da eficácia do sistema democrático, por um lado, e a convicção de que a ditadura seria mais eficiente na resolução dos problemas sociais básicos, por outro lado.

Finalmente, os resultados da regressão múltipla permitiram constatar como num contexto específico pode emergir a oposição ideológica entre materialismo e pós-materialismo. De fato, quanto mais os estudantes consideram os valores constitutivos do sistema pós-materialista importantes para a organização da sociedade mais esses estudantes são favoráveis à democracia e menos credibilidade eles atribuem à ditadura. Já a maior importância atribuída ao sistema materialista diminui a favorabilidade da democracia e aumenta o apoio dado ao retorno do sistema ditatorial. Contudo, os resultados revelaram que o poder explicativo dos sistemas de valores sobre a atitude democrática é baixo $\left(R^{2}=0,06\right)$. Isto indica a necessidade de, em futuras investigações, incrementar o modelo com a inclusão de outros preditores sócio-políticos, tais como a identificação partidária e o posicionamento no espectro político (esquerda versus direita). Mesmo assim, o padrão de relações constatado, além de confirmar as hipóteses sobre as direções nas relações dos sistemas materialista e pós-materialista com a atitude em relação à democracia, são consistentes com resultados verificados nos estudos desenvolvidos por Pereira e cols. (2001), aplicando a mesma perspectiva adotada neste artigo, e por Barnea e Schwartz (1998), que aplica outra abordagem para explicar como os valores de autotranscendência levam ao voto em partidos democráticos. Além disso, Inglehart (1991) descreve o pós-materialismo como uma das características centrais em um ambiente cultural propício à participação do cidadão nas decisões políticas e na luta em favor da consolidação das instituições democráticas e descreve o materialismo como essencial nas culturas onde predominam os sistemas antidemocráticos de organização da sociedade. Embora o estudo apresentado neste artigo, assim como os relatados em outras investigações (Moraes, 2002; Pereira \& cols., 2002) empregando o QVP-24 para avaliar as atitudes políticas, contribua com o acúmulo de conhecimentos sobre a organização dos valores e sua relação com a política, esses estudos apresentam uma limitação importante na medida em que são desenvolvidos, sobretudo, com amostra de estudantes universitários. Com base nessa preocupação, novos estudos estão sendo desenvolvidos com o QVP-24 e com a EARD-30 com o objetivo de desenvolver essa perspectiva em amostras de populações mais heterogêneas.

\section{Referências}

Abelson, R.P. (1967). A technique and a model of multi-dimensional attitude scaling. Em M. Fishbein (Org.), Readings in attitude: Theory and measurement (pp. 349-356). New York: Jonh Wiley e Sons.

Aldenderfer, M.S. \& Blashfield, R.K. (1984). Cluster analysis. Beverly Hills: Sage.

Baquero, M. (1994). Os desafios na construção de uma cultura política democrática na América Latina: Estado e partidos políticos. Em M. Baquero (Org.), Cultura política e democracia: Os desafios das sociedades contemporâneas (pp. 26-41). Porto Alegre: UFRGS.

Barnea, M.F. \& Schwartz, S.H. (1998). Values and voting. Political Psychology, 19(1), 17-40.

Bobbio, N. (1986). O futuro da democracia: Uma defesa das regras do jogo. São Paulo: Paz e Terra.

Bobbio, N. (1991). Três ensaios sobre a democracia. São Paulo: Cardim \& Alario.

Bobbio, N. (1993). Democracia. Em N. Bobbio, N. Matteucci \& G. Pasquino (Orgs.), Dicionário de política (Vol. 1, pp. 319-329). Brasília: Edunb.

Braithwaite, V. (1994). Beyond Rokeach's equality-freedom model: Two-dimensional values in a one-dimensional world. Journal of Social Issues, 50(1), 67-94.

Camino, L. (1996). Uma abordagem psicossociológica no estudo do comportamento político. Psicologia e Sociedade, 8(1), 16-42.

Camino, L., Torres, A.R. \& Da Costa, J. (1995). Voto, identificacion partidaria, identidad social e construccion de la ciudadania. Em O. D’Adamo, V. G. Beaudoux \& M. Montero (Orgs.), Psicología de la acción política (pp. 129-142). Buenos Aires: Paidós.

Cochrane, R., Billig, M. \& Hogg, M. (1979). British politics and the two-value model. Em M. Rokeach (Org.), Understanding human values: Individual and societal (pp. 179-191). New York: Free Press.

Cronbach, L. (1951). Coefficient alpha and the internal structure of tests. Psychometrika, 16(3), 297-334.

Da Costa, J.B. (2000). Visões sociais de democracia: Um estudo psicossociológico dos significados da democracia. Tese de Doutorado, Pontifícia Universidade Católica de São Paulo, São Paulo.

D’Adamo, O.J. \& Beaudoux, V.G. (1995). Actitudes hacia la democracia: Del modelo clásico liberal a las nuevas democracias participativas. Em O. D’Adamo, V. G. Beaudoux \& M. Montero (Orgs.), Psicología de la acción política (pp. 81-90). Buenos Aires: Paidós. 
De Riz, L. (1994). Os desafios da democracia argentina. Em M. Baquero (Org.), Cultura política e democracia: Os desafios das sociedades contemporâneas (pp. 55-75). Porto Alegre: UFRGS.

Deschamps, J.C. \& Devos, T. (1993). Valeurs, cultures et changement. Intercultures, 1(1), 17-28.

Doise, W. (1976). L'articulation psychosociologique et les relations entre groupes. Bruxelles: De Boeck.

Doise, W. (1982). L'explication en psychologie sociale. Paris: PUF.

Feather, N.T. (1979). Values correlates of conservatism. Journal of Personality and Social Psychology, 37(6), 1617-1630.

Feather, N.T. (1984). Protestant ethic, conservatism and values. Journal of Personality and Social Psychology, 46(6), 11321141.

Feather, N.T. (1989). Attitudes towards high achiever: The fall of the tall poppy. Australian Journal of Psychology, 41(2), 239-267.

Finkel, S., Sigelman, L. \& Humphries, S. (1999). Democratic values and political tolerance. Em J.P. Robinson, P.R. Shaver \& L.S. Wrightsman (Orgs.), Measures of political attitudes (Vol 2, pp. 203-296). New York: Academic Press.

Gibson, J., Duch, R. \& Tedin, K. (1992). Democratic values and the transformation of Soviet Union. Journal of Politics, 54 (2), 329-371.

Giner, S. (1986). La estrutura lógica de la democracia. Sistema, 70(1), 3-25.

Gouveia, R., França, D., Da Costa, J. \& Camino, L. (1997). O papel das crenças políticas no comportamento dos eleitores de João Pessoa em 1992 e 1994. Em L. Camino, L. Lhullier \& S. Sandoval (Orgs.), Estudos sobre comportamento político: Teoria e pesquisa (pp. 107-125). Florianópolis: Letras Contemporâneas.

Gouveia, V., Martínez, E., Meira, M. \& Milfont, T.L. (2001). A estrutura e o conteúdo universais dos valores humanos: Análise fatorial confirmatória da tipologia de Schwartz. Estudos de Psicologia, 6(2), 133-142.

Inglehart, R. (1977). The silent revolution. Princeton: Princeton University.

Inglehart, R. (1991). El cambio cultural en las sociedades industriales avanzadas. Madrid: Siglo XXI.

Inglehart, R. (1994). Modernización y post-modernización: La cambiante relación entre el desarrollo econômico, cambio cultural y político. Em J.D. Nícolas \& R. Inglehart (Orgs.), Tendencias mundiales de cambio en los valores sociales y políticos (pp. 157-170). Madrid: Fundesco.

Iñíquez, L. \& Vázquez, F. (1995). Legitimidad del sistema democrático: Análisis de un discurso autorreferencial. Em O. D'Adamo, V. G. Beaudoux \& M. Montero (Orgs.), Psicología de la acción política (pp. 35-64). Buenos Aires: Paidós.

Kaase, M. (1971). Demokratische Einstellung in der Bundesrepublik Deutschland. Em R. Wildenman (Org.), Sozialwissenschaftliches jahrbuch für politik (Vol. 2, pp. 119-326). Munich: Günter Olzog Verlag.

Kinder, D.R. \& Sears D.O. (1985). Public opinion and political action. Em G. Lindzey \& E. Aronso (Orgs.), The handbook of social psychology (pp. 659-742). New York: Random House.

Kruskal, J.B. \& Wish, M. (1978). Multidimensional scaling. London: Sage.

Lechner, N. (1994). Os novos perfis da política: Um esboço. Em M. Baquero (Org.), Cultura política e democracia: Os desafios das sociedades contemporâneas (pp. 11-24). Porto Alegre: UFRGS.

Lhullier, L. (1996). Socialização política na universidade: Participação, autoritarismo e democracia. Em L. Camino \& P.R. Menandro (Orgs.), A sociedade na perspectiva da psicologia: Questões teóricas e metodológicas (pp. 37-46). Rio de Janeiro: ANPEPp.

Likert, R. (1970). A technique for the measurement of attitudes. Em G.F. Summers (Org.), Attitude measurement (pp. 149-158). London: Kershaw.

Lima, M.E. (1997). Valores, participação política, atitudes face a democracia e ao autoritarismo: Uma análise da socialização política dos universitários da Paraíba. Dissertação de Mestrado, Universidade Federal da Paraíba, João Pessoa.

Lima, M.E. \& Camino, L. (1995). A Política na vida de estudantes universitários: Uma análise em termos de espaço político e de valores. Em M.J.L. Silva (Org.), Iniciados (pp. 11-35). João Pessoa: Editora Universitária.

Lipset, S.M. (1982). The academic mind at the top: The political behavior and values of faculty elites. Public Opinion Quarterly, 46(1), 143-168.

Macpherson, C.B. (1978). A democracia liberal: Origens e evolução. Rio de Janeiro: Zahar.

Maio, G.R. \& Olson, J.M. (1998). Values as truisms: Evidence and implications. Journal of Personality and Social Psychology, 74(2), 294-311.

McClosky, H. (1964). Consensus and ideology in American politics. American Political Science Review, 58(3), 361-382.

McClosky, H. \& Zaller, J. (1984). The American ethos: Public attitudes toward capitalism and democracy. Cambridge: University Press.

Miller, A., Hesli, V. \& Reisinger, W. (1995). Comparing citizen and elite belief systems in post-Soviet Russia and Ukraine. Public Opinion Quarterly, 59(1), 1-40.

Moraes, R. (2002). Práticas de socialização e valores sociais: Um estudo da relação entre a percepção das práticas parentais de socialização e os valores sociais de adolescentes paraibanos. Dissertação de Mestrado.

Offe, C. (1985). New social movements: Challenging the boundaries of institutional politics. Social Research, 52(4), 817-868.

Pasquali, L. (1999). Testes referentes a construto: Teoria e modelo de construção. Em L. Pasquali (Org.), Instrumentos psicológicos: Manual prático de elaboração (pp. 37-71). Brasília: Labpam.

Pereira, C. (2000). Princípios organizadores do envolvimento nos direitos humanos: análise dos sistemas de valores de universitários paraibanos. Dissertação de Mestrado.

Pereira, C. \& Camino, L. (1999). Proposta de um modelo psicossociológico para o estudo das atitudes políticas de estudantes universitários: Uma análise em termos de valores materialistas e pós-materialistas. Em M. F. V. Souza (Org.), Iniciados (pp. 427-440). João Pessoa: Editora Universitária.

Pereira, C., Camino, L., Da Costa, J., Lima, M.E., Lhullier, L. \& Sandoval, S. (2001). Sistemas de valores e atitudes democráticas de estudantes universitários do Sul do Brasil. Estudos, 28(4), 639- 671 .

Pereira, C., Da Costa, J. \& Camino, L. (2002). Desenvolvimento de uma abordagem societal para a análise dos sistemas de valores de estudantes universitários: O questionário de valores psicossociais QVP-24. Manuscrito submetido à publicação. 
Pereira, C., Lima, M.E. \& Camino, L (1997). A prática política: Uma análise psicossociológica em termos de valores e inserção social. Em M.J.L. Silva (Org.), Iniciados (pp. 199-235). João Pessoa: Editora Universitária.

Pereira, C., Lima, M.E. \& Camino, L. (2001). Sistemas de valores e atitudes democráticas de estudantes universitários de João Pessoa. Psicologia: Reflexão \& Crítica, 14(1),167-190.

Prothro, J. \& Grigg, C. (1960). Fundamental principles of democracy: Bases of agreement and disagreement. Journal of Politics, 22(1), 276-294.

Reisinger, W., Miller, A. Hesli, V. \& Maher, K. (1994). Political values and Russia, Ukraine and Lithuania: Sources and implications of democracy. British Journal of Political Science, 24(2), 183-223.

Rokeach, M. (1968). Beliefs, attitudes and values: A theory of organization and change. San Francisco: Jossey-Bass.

Rokeach, M. (1973). The nature of human values. New York: Free Press.

Rokeach, M. (1979a) Introduction. Em M. Rokeach (Org.), Understanding human values: Individual and societal (pp. 111). New York: Free Press.

Rokeach, M. (1979b). The two-value model of political ideology and British politics. Em M. Rokeach (Org.), Understanding human values: Individual and societal (pp. 192-196). New York: Free Press.

Schmitter, P. (1997). Perspectivas da democracia no mundo contemporâneo: Mais liberal, pré-liberal ou pós-liberal? Em S. Gerschman \& M.L.W. Viana (Orgs.), A Miragem da pósmodernidade: Democracia e políticas sociais no contexto da globalização (pp. 31-42). Rio de Janeiro: Fiocruz.

Schwartz, S.H. (1992). Universals in the content and structure of values: Theoretical advanced and empirical tests in 20 countries. Em M. Zanna (Org.), Advances in experimental social psychology (Vol. 25, pp. 1-65). Orlando: Academic Press.

Schwartz, S.H. (1994). Are there universal aspects in the structure and contents of human values? Journal of Social Issues, 50(1), $19-45$.

Schwartz, S.H. (1996). Value priorities and behavior: Applying a theory of integrated value systems. Em C. Seligman, J.M. Olson \& M.P. Zanna (Orgs.). The psychology of values: The Ontario Symposium (Vol. 8, pp. 1-24). Mahwah, NJ: LEA.

Schwartz, S.H. \& Bardi, A. (1997). Influences of adaptation to communist rule on value priorities in Eastern Europe. Political Psychology, 18(2), 385-410.

Schwartz, S.H. \& Bardi, A. (2001). Value hierarchies across cultures: Taking a similarities perspective. Journal of Cross-Cultural Psychology, 32(2), 268-290.

Tabchinick, B.G. \& Fidell, L. S. (1996). Using multivariate statistics. New York: Harper and Row.

Tamayo, A. \& Shwartz, S.H. (1993). Estrutura motivacional dos valores humanos. Psicologia: Teoria e Pesquisa, 9(2), 328346.

Tamayo, A., Pimenta, M., Rolim, M., Rodovalho, O. \& Castro, P. (1996). Prioridades axiológicas e orientação política. Psicologia: Teoria e Pesquisa, 12(3), 253-259.

Tetlock, P.E. (1986). A value pluralism model of ideological reasoning. Journal of Personality and Social Psychology, 50(4), 819-827.

Torres, A.R.R. (1992). Uma análise psicossocial da identificação partidária: $O$ caso dos estudantes da UFPb nas eleições de
1988, 1989 e 1990. Dissertação de Mestrado.

Torres, A.R.R., Pereira, C., Guimarães, J., Albernaz, M., Vieira, S. \& Barros, T. (2001). Valores e psicologia social: Modelos de análise. Estudos, 28(4), 539-559.

Touraine, A. (1996). O que é a democracia? Petrópolis: Vozes.

Ward, J. H. (1963). Hierarchical grouping to optimize an objective function. Journal of American Association, 58(2), 236-244.

Weil, F. (1989). The sources of structure of legitimation in Western democracies: A consolidated model tested with time-series data in six countries since World Ward II. American Sociological Review, 54(5), 682-706.

Weil, F. (1993). The development of democratic attitudes in eastern and western Germany in a comparative perspective. Em F. Weil (Org.), Research on democracy and society: Democratization in eastern and western Europe (Vol. 1, pp. 195-225). Greenwich: JAI Press.

Whitefield, S. \& Evans, G. (1996). Support of democracy and political opposition in Russia, 1993-1995. Pos-Soviet Affairs, 12(2), 218-242. 